\title{
Disability Studies
}

Canadian Journal of Disability Studies

Published by the Canadian Disability Studies Association Association Canadienne des Études sur le Handicap

Hosted by The University of Waterloo

www.cjds.uwaterloo.ca

cjdseditor@uwaterloo.ca 


\title{
Commentary: Shapes and sites of deaf people's transinstitutionalization \\ Kristin Snoddon, $\mathrm{PhD}$ \\ Associate Professor, School of Early Childhood Studies \\ Ryerson University \\ ksnoddon@ryerson.ca \\ Joanne Weber, PhD \\ Assistant Professor, Faculty of Education \\ University of Alberta \\ jweber1@ualberta.ca
}

\begin{abstract}
This commentary describes our perspective on transinstitutionalization as deaf teachers and researchers from different regions of Canada, and accounts for some of the ways in which transinstitutionalization manifests in the lives of deaf people, particularly in educational settings. In the present day, so-called inclusive education is often presented as the progressive alternative to institutionalization, or deaf schools. However, mainstream education in regular settings without adequate sign language support and the continuing polarization of language and identity options for deaf children are two of the main ways in which transinstitutionalization recurs for deaf children and adults and threatens the vitality of sign languages.
\end{abstract}

Keywords: Deaf education, sign language, inclusive education, early intervention 


\title{
Commentary: Shapes and sites of deaf people's transinstitutionalization
}

\author{
Kristin Snoddon, $\mathrm{PhD}$ \\ Joanne Weber, PhD
}

\section{Introduction}

The inspiration for writing this commentary came from an email exchange with the guest editors of the Canadian Journal of Disability Studies' special issue titled "Shapes and Sites of Transinstitutionalization." As deaf individuals and scholars of applied linguistics and deaf education, our attention was caught by the prominent inclusion and representation of deaf people in the first version of the call for papers for the special issue. While we appreciated this wording was intended in a spirit of inclusion of all members of the disability community (which we consider ourselves to be part of), we were concerned that the call for papers misrepresented our experiences. Accordingly, we contacted the editors because we objected to what we perceived to be the representation of deaf schools as "institutionalization" as a context similar to what other people with disabilities may experience. The constructive and respectful exchange we had with the editors has inspired us to further contemplate and attempt to outline what institutionalization and transinstitutionalization may mean for deaf people today, and the shapes and sites in which they may occur. In what follows, we outline our perspective on transinstitutionalization and some instances where it is seen to manifest in our respective contexts.

\section{A deaf perspective}

Transinstitutionalization recurs in the lives of deaf and disabled people who are impacted by all historic and current efforts to manage them. In this commentary, we will explore the ways in which transinstitutionalization recurs in the lives of deaf people, not only in the guise of socalled inclusive education that is centered around placement with nondeaf peers and without sign language, but also under the apex of neonatal hearing screening and early intervention programs. 
Both mainstreaming and early intervention for deaf and hard-of-hearing children, which focus mainly on auditory habilitation and spoken language development and often exclude sign language, are presented as the progressive alternative to "institutionalization" or schools for the deaf which enabled language, literacy, and socio-cultural development for many deaf individuals. In the present day, as in the recent past, the closure of deaf schools continues in Canada and internationally, despite reports that deaf children are not achieving at the same rate as their nondeaf peers in mainstream settings (e.g., Weale, 2016). Additionally, the nearuniversalization of cochlear implants is presented by educators and policymakers as the corrective to the problem of deaf children's educational, social, emotional, and linguistic needs. With cochlear implants, it is commonly believed, there is no longer a need for sign language or for implementing bilingual education programs with sign language as the language of instruction. Such programs, which emerged in the 1990s, represent a radical point of departure and a challenge to deaf education, which remains entrenched in systems of medicalization, audism, colonialism, and white supremacy.

\section{Saskatchewan}

In Saskatchewan, the deinstitutionalization movement began in the early 1960s and culminated in the 1991 closure of the R.J.D. Williams School for the Deaf in Saskatoon. Over a period of 28 years, transinstitutionalization of services for deaf children has included the transfer of responsibility for education from a provincial deaf school to school boards in various locales throughout the province, and for audiological and mental health services to local health authorities. Through the dispersal of a core group of deaf and hearing experts who were once employed by the school for the deaf, and who were skilled in various areas of education, mental 
health services, sign language interpreting, and vocational services for deaf children and youth, transinstitutionalization has negatively impacted the province's ability to provide core services from experts who are trained in serving deaf people and fluent in American Sign Language (ASL). Funding for social services targeted at people who communicate through ASL to learn, work, and participate in Canadian society is often tenuous and inadequate. Transinstitutionalization, therefore, is predicated on the assumption that any professional within the health, education, justice, or social services sector can adequately serve all deaf people of all ages, despite present-day diversity in modalities of communication, language and literacy levels, ethnicity, race, disability, and class. Thus, in various locales throughout the province, deaf people often must repeatedly explain their needs to professionals who are unfamiliar with deaf people. Over the past 28 years, the movement toward transinstitutionalization has resulted in an uneven patchwork of programs and services and a slow erosion of services. A Saskatchewan Human Rights Commission (2016) report featured accounts from parents of deaf children who testified that they did not receive information from health and education authorities about sign language, bilingual education for deaf learners, or the need for deaf role models as linguistic and cultural resources for families with deaf children.

\section{Ontario}

The devaluation of sign language and deaf communities is a central project of Canadian deaf education, as evidenced in Ontario's publicly funded teachers of the deaf training program, which does not uphold affirmative action policies for deaf teacher candidates that are enshrined in the Ontario College of Teachers Act (Ontario Regulation 184/97, s. 19). Aimed at increasing the number of deaf teachers in Ontario, this policy would otherwise allow deaf candidates with 
bachelor's degrees but without general Bachelor of Education qualifications to enroll in deaf education programs (Malkowski, 2005). In this way, transinstitutionalization perpetuates historical barriers to postsecondary education that are faced by deaf learners (Canadian Hearing Society, 2014). This practice also works to maintain century-old restrictions on deaf people becoming teachers of deaf learners (Carbin, 1996). Deaf teachers are essential not only to enacting bilingual education programs (since most deaf children lack access to proficient sign language models), but also to advocating for deaf children's needs and supporting children's acquisition of social and cultural capital that will enable them to live full lives (Kusters, 2017). Teacher education program policies that force candidates to choose between an aural/oral or ASL "stream" while failing to provide support for learning ASL make oralism and teaching in mainstream settings the default option for most candidates (Snoddon, in press). The historical segregation of deaf children by language modality, instigated by hearing teachers and administrators in schools for the deaf, continues in the present day in so-called inclusive settings. This segregation is also evoked by the small-d versus big-D binary for naming different kinds of deaf people, which we have come to reject on the grounds that as well as being divisive, it is "an oversimplification of what is an increasingly complex set of identities and language practices" (Kusters, De Meulder, \& O’Brien, 2017, p. 14).

\section{Intersectionality}

Recent research reveals that while an increasing number of deaf children today are nonwhite, the vast majority of educators of the deaf remain white and hearing (Cannon \& Luckner, 2016). Audism and racism, like disability and race, are not separate but intertwined; in Butler's (1999) words, “these categories always work as background for one another, and they 
often find their most powerful articulation through one another" (p. xvii). Mauldin (2016) points out that medical interventions such as cochlear implants and speech therapy benefit mainly white and middle-class families, while race, class, and additional disabilities are cited as reasons why many deaf children fail to acquire spoken language. In recent years, reports have surfaced in Saskatchewan that highlight the complexity of addressing language acquisition in deaf children and youth who are nonwhite, newcomer Canadians, or of Indigenous descent. For instance, a recent report by the Saskatchewan Advocate for Children and Youth featured the death in custody of Dylan Lachance, a deaf First Nations 16-year-old who due to language deprivation stemming from lack of opportunity to learn ASL was unable to communicate with staff responsible for his care (O'Soup, 2017; Pacholik, 2016, Pringle, 2016). Earlier, the Provincial Court of Saskatchewan's 2005 decision in the matter of the Child and Family Services Act of Saskatchewan and Ryley Allen Farnham described an eight-year-old deaf Indigenous student without written, spoken, or signed language abilities. Ryley was found by the court "to be a child in need of protection, on the sole ground that he has suffered a serious impairment of mental or emotional functioning" due to sign language deprivation (cited in Snoddon, 2009). These examples illustrate how present legal and human rights frameworks are inadequate for meeting deaf children's and youth's right to sign language (Paul \& Snoddon, 2017) and allow grievous human rights violations to continue in plain sight.

\section{Sign languages as endangered and exploited}

Due to the widespread effects of cochlear implants and mainstreaming, in the present day deaf scholars are beginning to employ the tools and rhetoric of language endangerment and revitalization in order to maintain sign languages and their intergenerational transmission (De Meulder, 2018; McKee, 2017; Snoddon, 2016; Snoddon \& De Meulder, 2020). A recent study 
by McKee (2017) assessed the vitality of New Zealand Sign Language (NZSL) by employing UNESCO's (2003) Language Vitality and Endangerment framework and the Expanded Graded Intergenerational Disruption Scale for sign languages (Bickford, Lewis, \& Simons 2015). This study found NZSL to have a "threatened" status, despite an increase in NZSL course offerings for second-language (i.e., mainly nondeaf) learners and constitutional recognition of NZSL (McKee, 2017). Like other countries in the Global North with relatively small populations and publicly funded health and education systems, Canada may be a bellwether for the decline in signing deaf communities and thus sign language endangerment (Johnston, 2004; McKee \& Smiler, 2017). This is so despite the Accessible Canada Act's recognition of ASL, Langue des signes québécoise, and Indigenous sign languages as primary languages for communication by deaf persons (Canada, 2019a; Snoddon \& Wilkinson, 2019; Snoddon \& Wilkinson, in press). Internationally, sign language recognition legislation tends to be largely symbolic and fails to include educational linguistic rights that include bilingual education programs and thereby sign language transmission to deaf children (De Meulder, 2016; McKee, 2017). Instead, the continuing medicalization of deaf communities is glimpsed in the reduction of sign language rights to "access" via a sign language interpreter as a hearing mediator of the majority spoken language. By way of contrast, Indigenous language rights in Canada do not centre around the provision of interpreting services (Ballingall, 2018). The inclusion of Indigenous sign languages in the Indigenous Languages Act is intended to support and promote the use of these languages and support the efforts of Indigenous peoples to reclaim, revitalize, maintain and strengthen all Indigenous languages, including Indigenous sign languages (Canada, 2019b). Similarly, the Official Languages Act mandates direct provision of federal government services in English and French, rather than via a French-English interpreter. The dominant culture's framing of sign 
language rights as a disability accommodation fails to meet the deeper cultural and linguistic needs of deaf people (Ladd, 2003).

Transinstitutionalization also recurs in the appropriation of sign languages for the financial benefit of nondeaf people. For example, scholars have noted that it is far easier for a nondeaf university or college student to gain access to a sign language class than it is for a parent of a deaf child or a deaf child herself (De Meulder, 2018; McKee \& Smiler, 2017). In Ontario, while school board resources are so constrained that an interpreter or signing educational assistant is denied to a primary-grade deaf child if she is not performing at least two years behind grade level (Boulet, L., personal communication, March 22, 2017), the same board's rollout of heritage language outside-of-school ASL classes has taken place virtually overnight (Ottawa Carleton District School Board, 2017). The ways in which learning ASL is afforded to hearing learners of all ages - from so-called baby sign programs to university-level classes-and simultaneously denied to deaf learners demonstrates how neoliberal educational and social service policies and practices spread across the state and market and therefore support transinstitutionalization.

\section{Conclusion: Promoting sites of linguistic, social, and cultural capital}

For many deaf and hard-of-hearing people, what is presented as "institutionalization" in the form of a deaf school is in fact often (but not always) a site of belonging, self-discovery, kinship, and home. Since their founding in the nineteenth century, schools for the deaf in Canada have provided sites of peer contact, language transmission, and cultural identity development. This was so even as educational philosophies shifted from nineteenth-century permissive attitudes toward sign languages under what was termed "manualism" or the "combined method" to the strict oralism that prevailed throughout the twentieth century, before the bilingual 
bicultural education movement that called for full implementation of sign languages across the curriculum in education for deaf children (Carbin, 1996). Thus, deaf schools hold high value for deaf communities. In stating this, we do not wish to gloss over the problems at schools for the deaf, including a history of abuse, separation from families, racism and racial segregation as well as segregation by language modality, and deaf children and adults' "long history as bodies under the control of institutions" (Padden \& Humphries, 2006, p. 56). Deaf schools, like deaf education itself, have rarely, if ever, been sites where deaf people hold the balance of power. Deaf people's histories and cultures are thus shaped by deaf communities' organized and unorganized resistance to power, and by the covert prestige sign languages continue to hold for these communities (Supalla \& Clark, 2015).

In writing this commentary, it is not our aim to provide an exhaustive overview of every way in which transinstitutionalization manifests in the lives of deaf people. Rather, we have described issues that preoccupy us as we engage "in a daily praxis, a continuing internal and external dialogue" about "what being a Deaf person in a Deaf community might mean" (Ladd, 2003, p. 3). In our professional and academic work as teachers and researchers, we have tried to enact solutions that confront transinstitutionalization by affording more chances for deaf youth and parents of deaf children to learn ASL and connect with deaf communities (Snoddon, 2015; Weber, 2020). These small-scale solutions are bottom-up rather than top-down, and remain quietly subversive. In dodging the efforts of many service providers to rehabilitate us into appearing more like hearing people, we have ironically learned that being less visible to those who perpetuate transinstitutionalization enables us to survive. From our positionalities within deaf communities, we look for ways to exercise agency while maintaining the linguistic, cultural, 
and social capital afforded by sign language and deaf people's congregation throughout all institutions. 


\section{References}

Ballingall, A. (2018, June 1). Ottawa planning law to recognized Indigenous language rights. Toronto Star. Retrieved from: https://www.thestar.com/news/canada/2018/06/01/ottawaplanning-law-to-recognize-indigenous-language-rights.html

Bickford, J., Lewis, M., \& Simons, G. (2015). Rating the vitality of sign languages. Journal of Multilingual and Multicultural Development, 36(5), 513-27. doi:doi:10.1080/01434632.2014.966827

Butler, J. (1999). Gender trouble: Feminism and the subversion of identity. New York, NY: Routledge.

Canada. (2019a). An act to ensure a barrier-free Canada, SC 2019 c 10.

Canada. (2019b). An act respecting Indigenous languages, SC 2019 c 23.

Canadian Hearing Society. (2014). Canadian Hearing Society's position paper on challenges and issues affecting access to post-secondary education for deaf and hard of hearing students. Toronto, ON: Canadian Hearing Society. Retrieved from https://www.chs.ca/sites/default/files/final_board_approved_chs_position_paper_on_post -secondary_education_nov_29_2014.pdf.

Cannon, J., \& Luckner, J. (2016). Increasing cultural and linguistic diversity in deaf education teacher preparation programs. American Annals of the Deaf, 161(1), 89-103. doi:10.1353/aad.2016.0014

Carbin, C. (1996). Deaf heritage in Canada: A distinctive, diverse and enduring culture. Toronto, ON: McGraw-Hill Ryerson.

De Meulder, M. (2016). Promotion in times of endangerment: The Sign Language Act in Finland. Language Policy, 16(2), 189-208. doi:10.1007/s10993-016-9403-5

De Meulder, M. (2018). "So, why do you sign?” Deaf and hearing new signers, their motivation, and revitalization policies for sign languages. Applied Linguistics Review. doi:doi: 10.1515/applirev-2017-0100

Johnston, T. (2004). W(h)ither the deaf community? Population, genetics and the future of Australian Sign Language. American Annals of the Deaf, 148(5), 353-375.

Kusters, A., De Meulder, M., \& O'Brien, D. (2017). Innovations in Deaf Studies: Critically mapping the field. In A. Kusters, M. De Meulder, \& D. O'Brien (Eds.), Innovations in Deaf Studies: The role of Deaf scholars (pp. 1-54). New York, NY: Oxford University Press. 
Kusters, M. (2017). Intergenerational responsibility in Deaf pedagogies. In A. Kusters, M. De Meulder, \& D. O'Brien (Eds.), Innovations in Deaf Studies: The role of Deaf scholars (Kindle ed.). New York, NY: Oxford University Press.

Ladd, P. (2003). Understanding deaf culture: In search of deafhood. Clevedon, UK: Multilingual Matters.

Malkowski, G. (2005). Response of the Canadian Hearing Society to the Ontario College of Teachers' Preparing teachers for tomorrow initial teacher education in Ontario.

Toronto, ON: Canadian Hearing Society.

Mauldin, L. (2016). Made to hear. Minneapolis, MN: University of Minnesota Press.

McKee, R. (2017). Assessing the vitality of New Zealand sign language. Sign Language Studies, 17(3), 322-362. doi:https://doi.org/10.1353/sls.2017.0008

O'Soup, C. (2017). Saskatchewan advocate for children and youth annual report. Retrieved from:

https://www.saskadvocate.ca/sites/default/files/u11/Advocate\%20for\%20Children\%20an d\%20Youth\%20Annual\%20Report\%20Final.pdf.

Ottawa Carleton District School Board. (2017). American Sign Language (ASL): OCDSB International Languages Program. Retrieved from http://ocdsb.ca/UserFiles/Servers/Server_55394/File/Continuing\%20Education/Internatio nal\%20Languages\%20Elementary/American\%20Sign\%20Language\%20(ASL).pdf.

Pacholik, B. (2016, June 16). Sask's child watchdog raises concerns over death of deaf child in youth custody facility. Regina Leader-Post. Retrieved from:

http://leaderpost.com/news/politics/sask-s-child-watchdog-raises-concerns-of-death-ofdeaf-child-in-youth-custody-facility.

Padden, C., \& Humphries, T. (2005). Inside Deaf culture. Cambridge: Harvard University Press.

Paul, J., \& Snoddon, K. (2017). Framing deaf children's right to sign language in the Canadian Charter of Rights and Freedoms. Canadian Journal of Disability Studies, 6(1), 1-27.

Pringle, B. (2016). The silent world of Jordan. Saskatoon, SK: Saskatchewan Advocate for Children and Youth.

Saskatchewan Human Rights Commission. (2016). Access and equality for Deaf, deaf, and hard of hearing people: A report to stakeholders. Saskatoon, SK: Ministry of Justice.

Snoddon, K. (2009). Equity in education: Signed language and the courts. Current Issues in Language Planning, 10(3), 255-271. 
Snoddon, K. (2015). Using the Common European Framework of Reference for Languages to teach sign language to parents of deaf children. Canadian Modern Languages Review, 71(3), 270-287. doi:10.3138/cmlr.2602

Snoddon, K. (2016). Whose ASL counts? Linguistic prescriptivism and challenges in the context of parent sign language curriculum development. International Journal of Bilingual Education and Bilingualism, 21(8), 1004-1015.

Snoddon, K. (in press). Sign language planning and policy in Ontario teacher education. In K. Snoddon, \& J. Weber (Eds.), Critical perspectives on plurilingualism in deaf education. Bristol, UK: Multilingual Matters.

Snoddon, K. \& De Meulder, M. (2020). Introduction: Ideologies in sign language vitality and revitalization. Language \& Communication, 74, 154-163. https://doi.org/10.1016/j.langcom.2020.06.008

Snoddon, K., \& Underwood, K. (2014). Toward a social relational model of Deaf childhood. Disabilty and Society, 29, 530-542.

Snoddon, K. \& Wilkinson, E. (2019). Problematizing the legal recognition of sign languages in Canada. Canadian Modern Language Review, 75(2) 128-144. https://doi.org/10.3138/cmlr.2018-0232

Snoddon, K. \& Wilkinson, E. (in press). Vulnerabilities, challenges, and risks in sign language recognition in Canada. In C. Cunningham \& C. Hall (Eds.), Taking risks in applied linguistics. Bristol, UK: Multilingual Matters.

Supalla, T., \& Clark, P. (2015). Sign language archaeology: Understanding the historical roots of American Sign Language. Washington, DC: Gallaudet University Press.

Weale, S. (2016, January 21). Deaf children lagging behind hearing peers in GCSEs. The Guardian. Retrieved from: https://www.theguardian.com/society/2016/jan/21/deafchildren-lagging-behind-hearing-peers-in-geses

Weber, J. (2020). Interrogating local sign language ideologies in the Saskatchewan deaf community: An autoethnography. In M. Green, A. Kusters, E. Moriarity-Harrelson, \& K. Snoddon (Eds.), Sign language ideologies in practice. Nijmegen, Netherlands: Mouton De Gruyter / Ishara Press. 